The original published PDF available in this website:

https://onlinelibrary.wiley.com/doi/abs/10.1002/adem.201800343

\title{
Effect of lithiation on the microstructure of a cobalt foam processed by freeze casting **
}

By Jenö Gubicza, Regina Németh, Hyeji Park, Kyungbae Kim, Jae-Hun Kim, Mihály Óvári, Miklós Mohai and Heeman Choe

[*] Prof. Dr. Heeman Choe, Ms. Hyeji Park, Ms. Kyungbae Kim, Dr. Jae-Hun Kim, School of Materials Science and Engineering, Kookmin University, 77 Jeongneung-ro, Seongbukgu, Seoul 02707, Republic of Korea

E-mail:heeman@kookmin.ac.kr

Prof. Dr. Jenö Gubicza, Ms. Regina Németh

Department of Materials Physics, Eötvös Loránd University, P.O.B.32, Budapest, H-1518, Hungary Dr. Mihály Óvári

MTA Centre for Ecological Research, Institute for Danube Research, H-1113, Budapest, Karolina út 29.

Dr. Miklós Mohai

Institute of Materials and Environmental Chemistry, Research Centre for Natural Sciences, Hungarian Academy of Sciences, Magyar tudósok körútja 2., Budapest, H-1117, Hungary

\section{[**] Acknowledgements}

J. Gubicza is grateful to Mr. Gábor Varga for the EBSD investigations and Prof. Gyula Záray for his suggestions. H. Choe also acknowledges support from the National Research Foundation (NRF) of Korea (2009-0093814, 2014R1A2A1A11052513). H. Park and K. Kim acknowledge the support of the NRF-Fostering Core Leaders of the Future Basic Science Program/Global Ph.D. Fellowship Program from the National Research Foundation (NRF) of Korea (2016H1A2A1909161, 2017H1A2A1043359). This work was financed partly by the Ministry of Human Capacities of Hungary within the ELTE University Excellence program (1783-3/2018/FEKUTSRAT).

\section{Abstract}

Surface-oxidized Co is a promising candidate as a negative electrode material in lithium ion batteries (LIBS). The stability of electrode materials in LIBs during charging/discharging is crucial from the viewpoint of their applications. In this study, experiments were carried out to investigate the influence of lithiation on the microstructure of Co foam processed by freeze casting. The main phase in the strut interiors of the as-prepared foam was hcp-Co with a grain size of $\sim 0.38 \mu \mathrm{m}$ and a considerable lattice strain. Thirty cycles of charging/discharging caused no changes in the phase composition, the grain size and microstrain in the struts. However, the crystalline surface oxide layer was practically amorphized and a strong oxygen/cobalt ratio gradient developed during 
lithiation; additionally, the foam was enriched with Li. These changes led to a fragmentation of the surface into scutes.

\section{Introduction}

With the considerable development of mobile electronic devices, large-scale energy storage systems and electric vehicles, there is an urgent demand for high-energy-density rechargeable batteries. ${ }^{[1,2]}$ Lithium ion batteries (LIBs) currently dominate the present-day market owing to their relatively high energy density, excellent cycle life, and reasonable cost. ${ }^{[1]}$ However, to meet the ever-growing energy demand from consumers, the energy density of batteries should be further increased. To achieve meaningful improvement in the energy density of LIBs, the development of high-capacity electrode materials is essential. Currently, graphite materials are the most widely used commercial negative electrodes (anodes) for LIBs due to their low operating potential and excellent cycling stability. However, their relatively low specific capacity of $372 \mathrm{mAh} \mathrm{g}^{-1}$ (for the $\mathrm{LiC}_{6}$ phase) after full lithiation is less than the market needs. In other words, the capacity of graphite is intrinsically limited because it is based on intercalation chemistry for Li ion storage. ${ }^{[3,4]}$

As a promising alternative, insertion-type systems such as Li-alloy-based materials or conversion-type systems such as transition-metal oxides have been actively investigated to replace graphite anodes. ${ }^{[5-11]}$ Among them, conversion-type cobalt (Co) oxide materials, such as $\mathrm{Co}_{3} \mathrm{O}_{4}$ and $\mathrm{CoO}$, have recently attracted great attention owing to their high theoretical capacity of $890 \mathrm{mAh} \mathrm{g}^{-1}$ and $715 \mathrm{mAh} \mathrm{g}^{-1}$, respectively. ${ }^{[12-18]}$ Such transition-metal oxides (MO, where $\mathrm{M}=\mathrm{Co}, \mathrm{Ni}, \mathrm{Cu}$, or Fe) have reversible capacities approximately three times higher than that of graphite. However, promising transition-metal oxide materials often show poor capacity retention during cycling, mainly due to the considerable volume expansion of the electrode during lithiation. Two main potential solutions have been reported to resolve these problems: using (i) a three-dimensional porous metal oxide anodes or (ii) a metal oxide/carbon nanocomposite. ${ }^{[19-23]}$ In particular, it is well known that both the architecture of the transition-metal oxide anode material and the structure of 
the current collector can considerably influence the electrochemical performance. ${ }^{[17-21,24-26]}$ For example, the combination of a nanostructured transition-metal oxide active material and a porous current collector is structurally advantageous both in controlling severe volume changes that occur in the anode and in improving electrochemical reactions due to the enlarged surface area from the pores. $^{[17,26]}$

Due to the importance of high-capacity transition-metal oxide electrodes, it is essential to investigate the microstructural evolution and phase changes induced by lithiation/delithiation. In the present study, lithiation-induced changes in the microstructure of Co foam with Co oxide surface layer are investigated. The foam was processed by freeze casting. The evolution of the phase composition and microstructure during 30 cycles of charging/discharging is studied in both the strut interiors and the surface oxide layer using scanning electron microscopy, electron back-scattered diffraction, and X-ray line profile analysis. To the knowledge of the authors, this is the first study in the literature which investigates the effect of lithiation/delithiation on the microstructure of a surface oxidized Co foam processed by freeze casting.

\section{Experimental material and procedures}

\subsection{Sample preparation}

A powder slurry was prepared from $30 \mathrm{ml}$ deionized water consisting of $8 \mathrm{vol} . \% \mathrm{Co}_{3} \mathrm{O}_{4}$ powder with $99.9 \%$ purity and an average particle size of $\sim 30 \mathrm{~nm}$ (manufacturer: Inframat Advanced Materials, USA). Additionally, a polyvinyl alcohol (PVA) binder with a fraction of 8 wt.\% (calculated with respect to the $\mathrm{Co}_{3} \mathrm{O}_{4}$ powder) was added to the slurry (manufacturer: SigmaAldrich Co., USA). The slurry was processed with a combination of stirring and sonication to improve the degree of dispersion. The slurry was then poured into a Teflon mold placed on a copper rod. The temperature at the top of the copper rod was fixed at $-10^{\circ} \mathrm{C}$ using liquid nitrogen and a heater. After the slurry was completely frozen, the ice was sublimated at $-88^{\circ} \mathrm{C}$ for $48 \mathrm{~h}$ in a vacuum, resulting in a green body. Then, the Co oxide green body was transformed to pure Co and 
sintered in a tube furnace under an $\mathrm{Ar}-5 \% \mathrm{H}_{2}$ gas mixture at high temperatures. The reduction and sintering processes consisted of two steps: (i) annealing at $550{ }^{\circ} \mathrm{C}$ for $4 \mathrm{~h}$ to remove the binder and reduce Co oxide to metallic Co and (ii) sintering the Co foam at $1000{ }^{\circ} \mathrm{C}$ for $3 \mathrm{~h}$. The as-prepared Co foam was cut into $300 \mu \mathrm{m}$ thick coins to be used as positive electrodes in LIBs. In order to grow Co oxide layer on the surface of the Co foam coin, the foam sample was heat-treated in air at $600{ }^{\circ} \mathrm{C}$ for $5 \mathrm{~min}$ in an electric furnace.

Without the standard use of a binder and a conductive material, the electrochemical performance of the prepared Co foam anode sample was evaluated with a coin-cell test carried out in an Ar-filled glove box. The working electrodes were cut into disc coupons approximately $11 \mathrm{~mm}$ in diameter and $300 \mu \mathrm{m}$ in width. As a standard test, Li foil was used as both the counter and reference electrodes. The tests were carried out with CR2032 coin-type half cells using $1.0 \mathrm{M} \mathrm{LiPF}_{6}$ in a solution of ethylene carbonate (EC) / diethylene carbonate (DEC) (3:7 volume ratio, PANAX Etec), which was used as the electrolyte with a porous polypropylene separator (Asahi Kasei Chemicals). The cells were tested galvanostatically using a constant current of $100 \mathrm{~mA} \mathrm{~g}^{-1}$ and a voltage window between $3.0 \mathrm{~V}$ and $0.01 \mathrm{~V}$ vs. $\mathrm{Li}^{+} / \mathrm{Li}$ at $25^{\circ} \mathrm{C}$ on a battery test system (CTS-Lab, BaSyTec, Germany) for 30 cycles. The results of these tests are not presented in this paper as they are out of the scope of this study. For materials characterization, the cells were disassembled in the charged state (delithiated) in an Ar-filled glove box. The Co foam electrode sample was washed in pure DEC solution and dried under vacuum.

\subsection{Characterization of the microstructure}

The density of the samples was determined as the ratio of the mass and the volume of the specimens rather than by the Archimedes' principle due to their open-cell structure. Therefore, the volume was calculated from the dimensions of the specimens measured with a micrometer screw gauge. The phase composition in the foam was investigated by X-ray diffraction (XRD) using a Philips Xpert powder diffractometer with $\mathrm{CuK} \alpha$ radiation (wavelength: $\lambda=0.15418 \mathrm{~nm}$ ). 
The microstructure of the Co foam disks was studied with cross-sections cut perpendicular to the freezing direction by scanning electron microscopy (SEM) using a FEI Quanta 3D electron microscope. In addition, electron back-scattered diffraction (EBSD) was used for the investigation of the grain size distribution in the struts of the foams. Rectangular areas of $100 \mu \mathrm{m}^{2}$ were etched into the strut material with a focused ion beam (FIB) of $\mathrm{Ga}^{+}$ions with an inclination angle of $6^{\circ}$ using an accelerating voltage of $30 \mathrm{kV}$ and an ion current of $15 \mathrm{nA}$. The step size in the EBSD experiments was set at $40 \mathrm{~nm}$. The detected inverse pole figures (IPFs) were evaluated using the OIM software to determine the grain size distribution.

The changes in the coherently scattering domain size and the lattice strain in the Co foams due to lithiation/delithiation cycles were studied by X-ray line profile analysis. The X-ray diffraction line profiles were measured using a high-resolution diffractometer with $\operatorname{CoK} \alpha_{1}$ radiation (wavelength: $\lambda$ $=0.1789 \mathrm{~nm})$. Two-dimensional imaging plates detected the Debye-Scherrer diffraction rings. The line profiles were determined as the intensity distribution perpendicular to the rings. The instrumental pattern was measured on $\mathrm{LaB}_{6}$ line profile standard material. The peak breadth was evaluated using the Williamson-Hall method, where the Full Width at Half Maximum (FWHM) is plotted as a function of the magnitude of the diffraction vector $(g) .{ }^{[27]}$ The intercept and the slope of the straight line fitted to the data yielded the coherently scattering domain size and the lattice strain, respectively. The instrumental correction was carried out by subtracting the FWHM values measured on the $\mathrm{LaB}_{6}$ standard material from the peak breadths obtained for the studied foams.

\subsection{Measurement of the Li content in the Co foam}

The Li content of the Co foam subjected to 30 cycles of lithiation/delithiation was determined by inductively coupled plasma-mass spectrometry (ICP-MS). Approximately $37 \mathrm{mg}$ of the sample was weighed into a Metal Free ${ }^{\mathrm{TM}}$ polypropylene centrifuge tube (VWR, Leuven, Belgium) and subjected to acid digestion. In the first step, $2 \mathrm{~mL}$ of $1: 1$ diluted $\mathrm{HCl}$ had been added to the sample before it was immersed in a water bath at $80^{\circ} \mathrm{C}$ for $24 \mathrm{~h}$. The supernatant was than decanted into 
another tube of the same type. To obtain the solid residue, $2 \mathrm{~mL}$ of $\mathrm{HNO}_{3}$ and $1 \mathrm{~mL}$ of $\mathrm{H}_{2} \mathrm{O}_{2}$ solution were added and dissolution was continued under the same conditions for $24 \mathrm{~h}$. After cooling, the clear digested solution was mixed with the $\mathrm{HCl}$ soluble fraction and filled up to $15 \mathrm{~mL}$ with deionized water. Afterward, $0.15 \mathrm{~mL}$ of this stock solution was pipetted in a new polypropylene tube, scandium internal standard was added to the solution and it was made up to 15 $\mathrm{mL}$ with deionized water. A blank sample was prepared in the same manner. The determination of Li content was carried out using a PlasmaQuant Elite (Analytik Jena, Germany) ICP-MS device. The raw data from the spectrometer were corrected with the internal standard and the corresponding blank was subtracted. The concentration was determined against a 7-point calibration line.

Li content in the uppermost surface layer of the Co foam subjected to 30 cycles of lithiation was determined by X-ray photoelectron spectroscopy (XPS). The spectra were recorded on a KratosXSAM 800 spectrometer operated at a fixed analyzer transmission mode, using $\mathrm{MgK} \alpha_{1,2}$ $(1253.6 \mathrm{eV})$ excitation. The pressure in the analysis chamber was lower than $1 \times 10^{-7} \mathrm{~Pa}$. The linearity of the energy scale was calibrated by the dual $\mathrm{Al} / \mathrm{Mg}$ anode method, setting a $233.0 \mathrm{eV}$ kinetic energy difference between the two $\mathrm{Ag} 3 \mathrm{~d}_{5 / 2}$ lines. Survey spectra were recorded in the 150 $1300 \mathrm{eV}$ kinetic energy range with $0.5 \mathrm{eV}$ steps. The high-resolution photoelectron lines of the main constituent elements were recorded by $0.1 \mathrm{eV}$ steps during $1 \mathrm{~s}$ dwell time. Spectra were referenced to the energy of the $\mathrm{C} 1 \mathrm{~s}$ line of the adventitious carbon, set at $284.6 \pm 0.1 \mathrm{eV}$ binding energy. The spectra were acquired and processed by the Kratos Vision 2 software package. Area intensity data were obtained after Shirley type background removal. The quantitative analysis was performed by the XPS MultiQuant 7.7 program using the experimentally determined photo-ionisation crosssection data of Evans et al. and asymmetry parameters of Reilman et al. ${ }^{[28-30]}$

\section{Results}

\subsection{Microstructure of the Co foam before and after lithiation}

Figure 1a shows a SEM image for the as-prepared Co foam taken on a surface cut perpendicular 
to the freezing direction. Large elongated pores with lengths and thicknesses of about 200 and 50 $\mu \mathrm{m}$, respectively, were observed. The relative density was about $22.6 \%$, which corresponds to a porosity of $77.4 \%$.
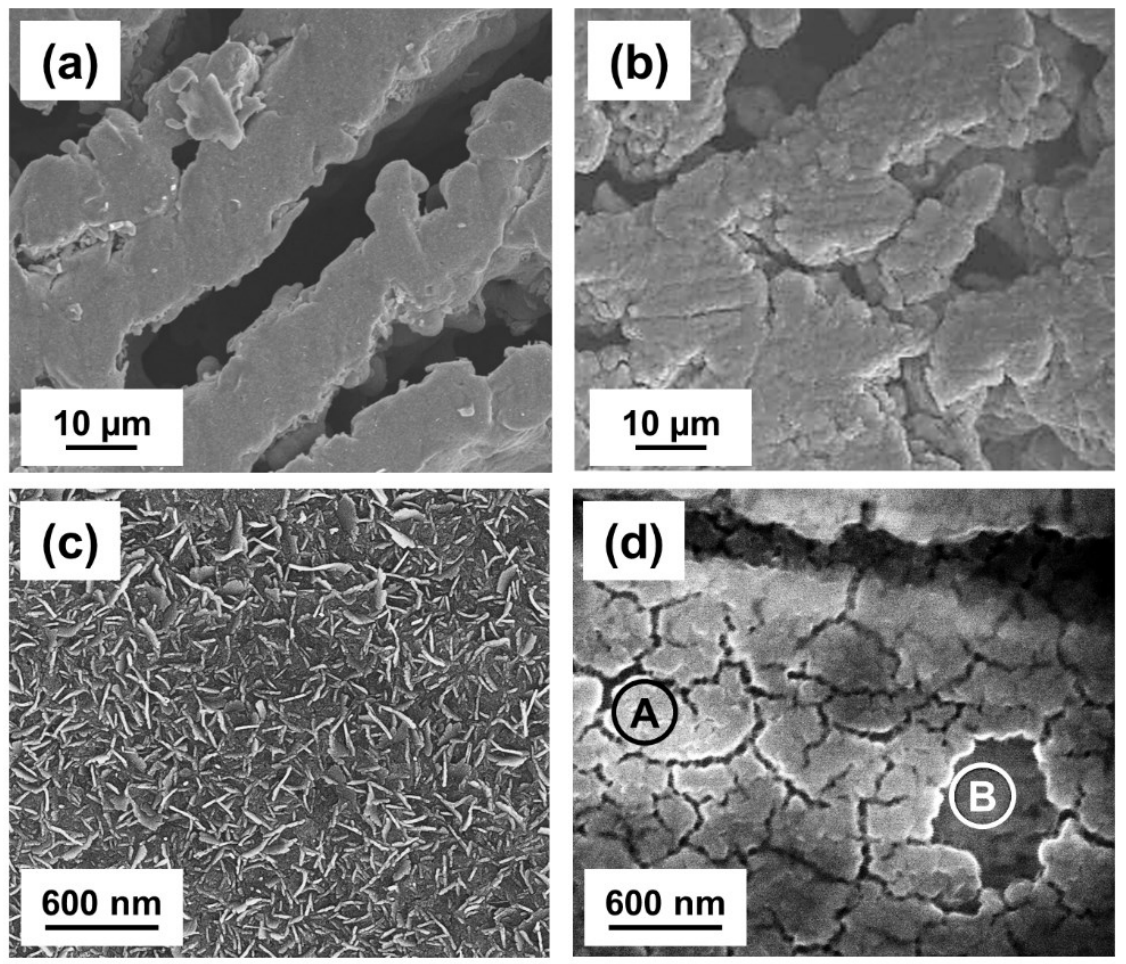

Figure 1. SEM images obtained for $(a, c)$ as-processed Co foam and $(b, d)$ after 30 cycles of lithiation.

Figure 2 shows part of the XRD pattern for the as-prepared sample (in the scattering angle range $\left.2 \theta=30-70^{\circ}\right)$. Analysis of the XRD peaks revealed that the as-prepared material contains hcp(PDF: 01-1278) and fcc-Co (PDF: 15-0806), $\mathrm{Co}_{3} \mathrm{O}_{4}$ (PDF: 43-1003) and $\mathrm{CoO}$ (PDF: 43-1004). The fractions of the crystalline phases were estimated using the integrated intensity fractions of these phases in the entire XRD pattern (in the scattering angle range of $2 \theta=10-140^{\circ}$ ). The integrated intensities were determined as the area under the peaks obtained after background subtraction. 


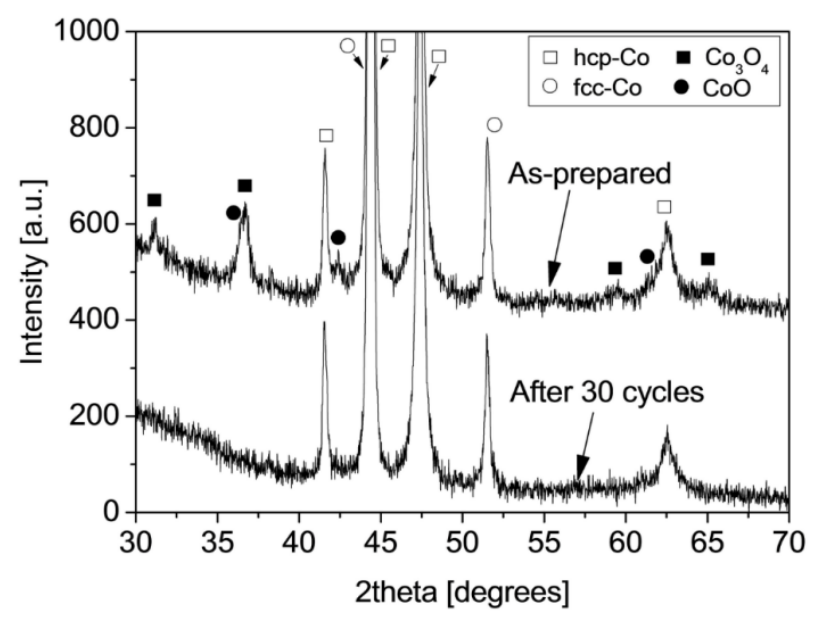

Figure 2. Parts of the XRD patterns obtained by $\mathrm{CuK} \alpha_{1}$ radiation for the as-prepared Co foam and after 30 cycles of lithiation.

Table 1 shows that the main phase was hep-Co with the intensity fraction of $\sim 84 \%$. The intensity fraction for the fcc-Co phase was one order of magnitude lower (about 9\%). The fraction of the $\mathrm{Co}_{3} \mathrm{O}_{4}$ phase was $\sim 6 \%$ while the fraction of the $\mathrm{CoO}$ phase was negligible $(\sim 1 \%)$. These cobalt oxide phases were most probably formed on the surface of the struts during the oxidation step of the Co foam production. This surface oxide layer is detailed in the next section of this paper.

Table 1. The phase composition and the grain size determined using XRD and EBSD, respectively, for the as-prepared Co foam and after 30 cycles of lithiation.

\begin{tabular}{|c|c|c|c|c|c|c|}
\hline & \multicolumn{4}{|c|}{ As-prepared } & \multicolumn{2}{c|}{ After 30 cycles } \\
\cline { 2 - 7 } & hcp-Co & fcc-Co & $\mathrm{Co}_{3} \mathrm{O}_{4}$ & $\mathrm{CoO}$ & hcp-Co & fcc-Co \\
\hline $\begin{array}{c}\text { Phase } \\
\text { composition } \\
{[\%]}\end{array}$ & 84 & 9 & 6 & 1 & 90 & 10 \\
\hline $\begin{array}{c}\text { Grain size } \\
{[\mu \mathrm{m}]}\end{array}$ & $0.38 \pm 0.04$ & $0.29 \pm 0.04$ & - & - & $0.28 \pm 0.04$ & $0.27 \pm 0.04$ \\
\hline
\end{tabular}

The grain structure of the struts was investigated using EBSD on an ion-milled area. Figure 3a and $\mathrm{b}$ show IPF images for the hcp- and fcc-Co phases, respectively. Co oxide phases were not observed in the IPF image, suggesting that these phases can be found only in the uppermost surface 
layer of the struts. In accordance with the XRD phase analysis, the majority of the struts comprised hcp-Co in the IPF image.

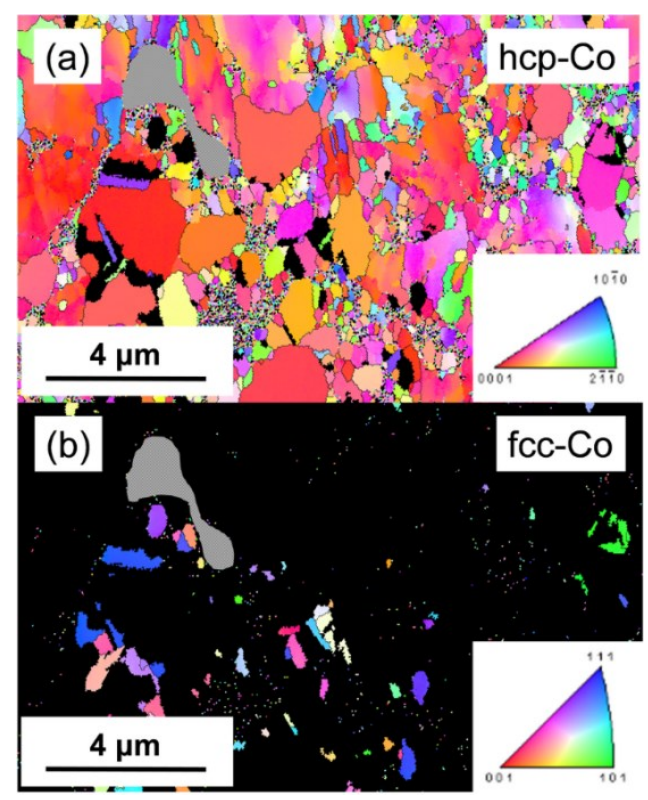

Figure 3. EBSD IPF images for (a) the hcp-Co and (b) the fcc-Co phases in the strut interiors of the as-prepared Co foam.

Moreover, the grain size distributions for the hcp- and fcc-Co phases in the as-prepared Co foam are shown in Figure $4 a$ and b, respectively. The majority of the grains in both phases are smaller than $1 \mu \mathrm{m}$. In the hcp-Co phase, some grains larger than $1 \mu \mathrm{m}$ can also be found in the distribution. Therefore, the average grain size of the hcp-Co phase $(0.38 \pm 0.04 \mu \mathrm{m})$ was slightly larger than that of the fcc-Co $(0.29 \pm 0.04 \mu \mathrm{m})$. The grain sizes are also listed in Table 1 .

The pore structure after 30 cycles of lithiation is shown in Figure 1b. Significant changes in the pore size and morphology were not observed. The relative density also remained unchanged.

Lithiation resulted in the disappearance of the oxide peaks in the XRD pattern, as shown in Figure 2. The absence of crystalline oxide peaks suggested amorphization of the surface oxide layer. It is noted, however, that if the grain size of the phases in the surface layer was only about $1 \mathrm{~nm}$, the corresponding diffraction peaks were invisible in the XRD pattern. This will be discussed in section 4. The ratio of the hcp- and fcc-Co phases remained the same (roughly nine) during lithiation (see Table 1). 

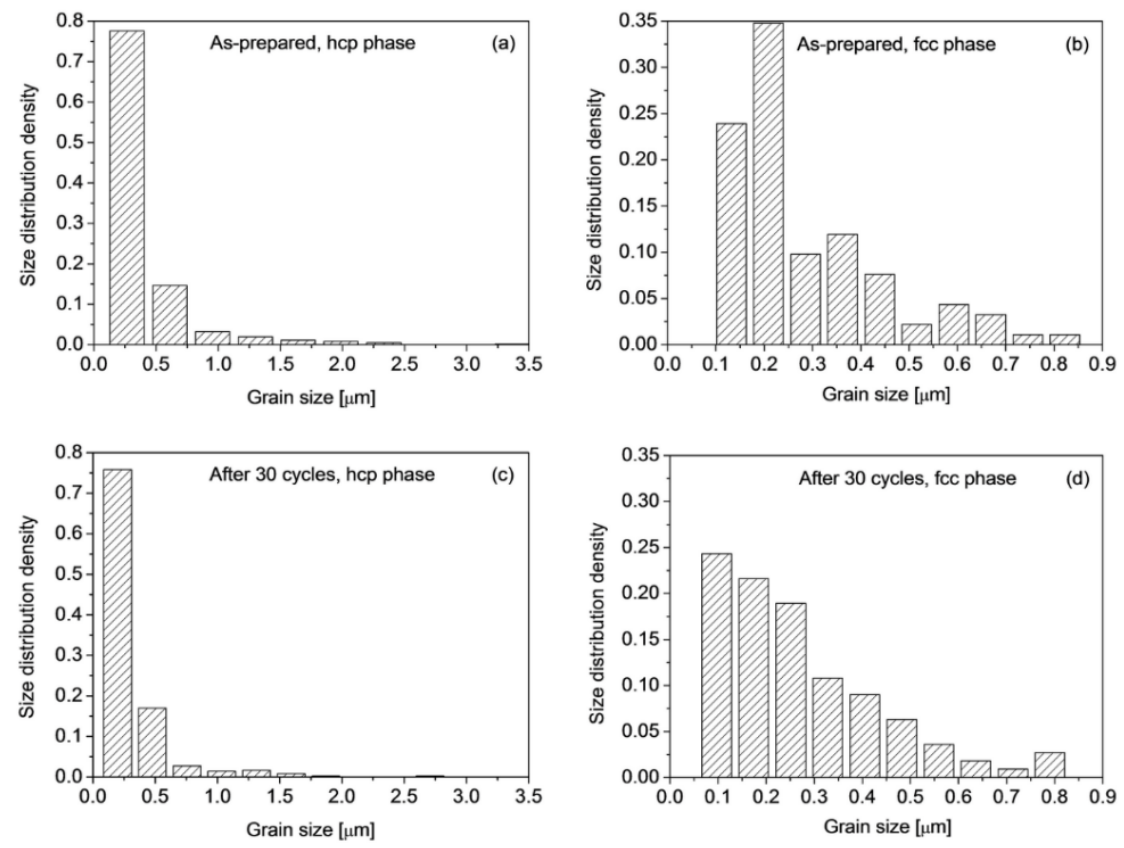

Figure 4. Grain size distributions for $(a, c)$ the hcp-Co and $(b, d)$ the fcc-Co phases in the strut interiors of the as-prepared Co foam and after 30 cycles of lithiation.

Figure 5a and $\mathrm{b}$ show the grain structure for the hcp- and fcc-Co phases in the strut interiors, respectively. The corresponding grain size distributions are shown in Figure 4c and d, respectively. Only very small differences between the average grain sizes of the hcp-Co phase was found before and after lithiation (see Table 1), which may have been caused by the slight spatial variation of the microstructure in the struts. The grain size of the fcc-Co phase remained unchanged within the experimental error during lithiation.

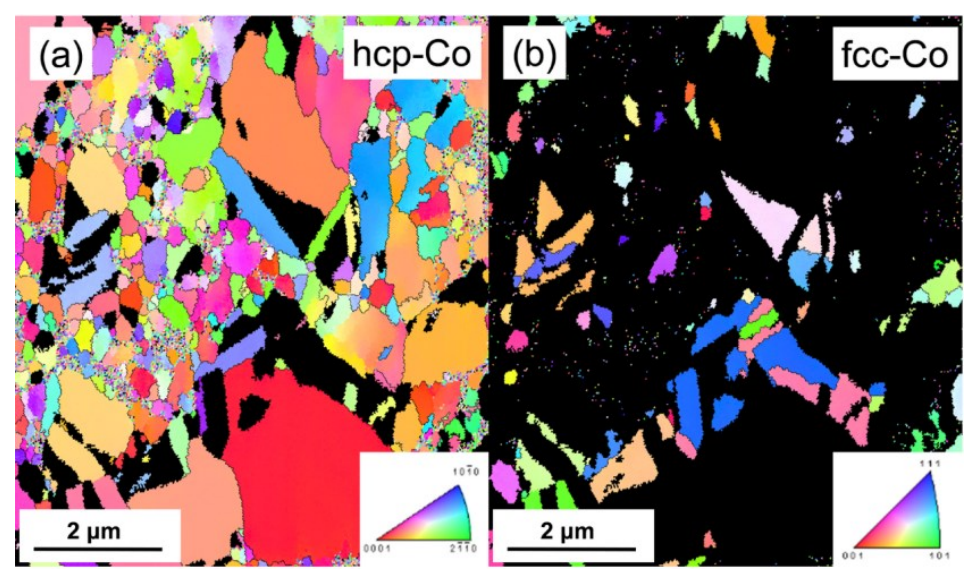

Figure 5. EBSD IPF images for (a) the hcp-Co and (b) the fcc-Co phases in the strut interiors of the Co foam subjected to 30 cycles of lithiation. 
The effect of lithiation on the coherently scattering domain size and the lattice strain in the major phase (hcp-Co) was investigated through analysis of the XRD line profiles. Figure 6 shows the Williamson-Hall plots obtained for the as-prepared Co foam and the sample subjected to 30 cycles of lithiation. Considerable differences between the two specimens were not observed. FWHM values exhibit strong diffraction anisotropy, i.e., the peak breadth depends strongly on the indices of reflections. Without this anisotropy, the FWHM values would follow a smooth curve as a function of the magnitude of the diffraction vector $(g)$. Figure 6 reveals that reflections with similar $g$ values have very different FWHM values. This behavior can be caused by the anisotropic strain field of lattice defects, such as dislocations and/or planar faults (e.g., twin or stacking faults). ${ }^{[27]}$ In addition, diffraction domains with an anisotropic shape may also result in an $h k l$ dependence of the peak breadth ( $h k l$ are the indices of reflections). In these cases, only the harmonic reflection points associated with the same crystallographic orientation (e.g., 100 and 200) can be evaluated from the conventional Williamson-Hall plot. Figure 6 shows straight lines fitted to the harmonic reflection pairs 100-200,002-004 and 101-202. For the as-prepared Co foam, the intercepts and the slopes of these straight lines are in the ranges of $0.002-0.01 \mathrm{~nm}^{-1}$ and $1.2-6.7 \times 10^{-3}$, respectively. The reciprocal of the intercept gives the apparent size of the coherently scattering domains. ${ }^{[27]}$ For the as-prepared Co foam, this size varies between 0.1 and $0.5 \mu \mathrm{m}$ in accordance with the grain size determined using EBSD. This result suggests that the grains in the struts are not fragmented into subgrains in the studied Co foam. It is noted that the volume studied with XRD line profile analysis was about six orders of magnitude larger than that inspected with EBSD. The lattice strain can be obtained from the slope of the fitted straight lines with division by $2.5 .^{[24]}$ Therefore, the lattice strain in the as-prepared foam varies between 0.5 and $2.7 \times 10^{-3}$. Most probably, this strain is caused by lattice defects as suggested by the observed strain anisotropy; however, investigation of these defects is out of the scope of the present study. Lithiation did not result in considerable changes in either the domain size or the lattice strain (see Figure 6). 


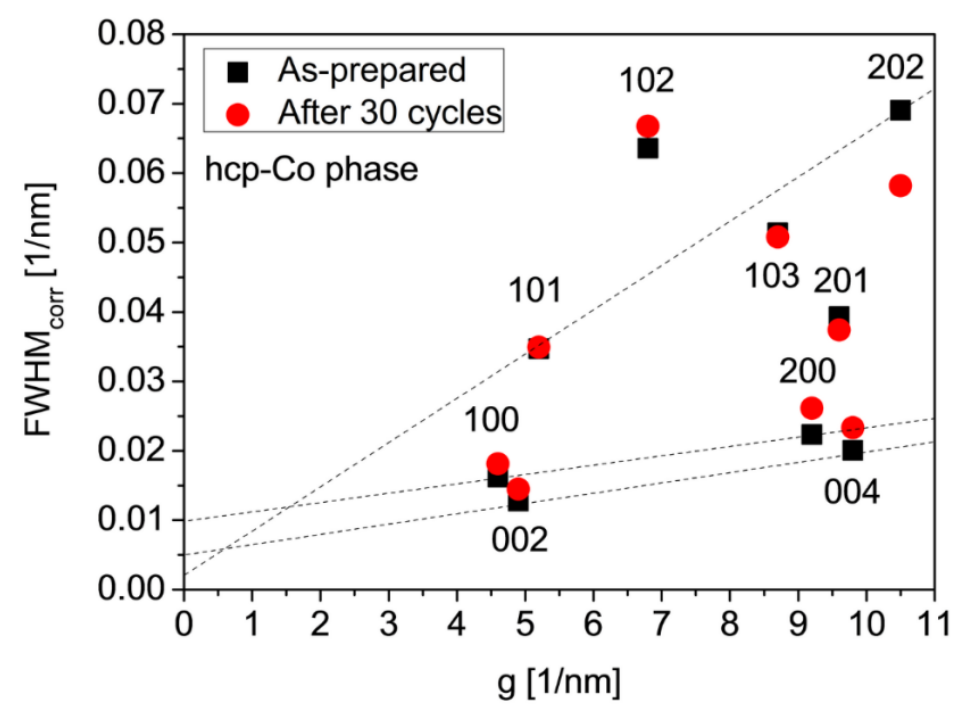

Figure 6. FWHM versus the magnitude of the diffraction vector for the XRD peaks of the hcp-Co phase in the as-prepared Co foam and after 30 cycles of lithiation (Williamson-Hall plots). The FWHM values are corrected for instrumental broadening.

\subsection{Changes in the surface oxygen layer during lithiation}

The XRD pattern for the as-prepared Co foam revealed that the sample contains crystalline $\mathrm{Co}_{3} \mathrm{O}_{4}$ and $\mathrm{CoO}$ with intensity fractions of about 6 and 1\%, respectively. Energy Dispersive Spectroscopy (EDS) measurement carried out with an electron energy of $5 \mathrm{keV}$ gave an oxygen concentration of about $52 \pm 1$ at.\% (see Table 2), which is close to the value estimated from the oxide phase content (56 at.\%). The penetration depth of electrons with the energy of $5 \mathrm{keV}$ in $\mathrm{Co}_{3} \mathrm{O}_{4}$ is about $0.2 \mu \mathrm{m}$ as estimated from the density of this oxide phase $\left(6.056 \mathrm{~g} \mathrm{~cm}^{-3}\right)$. Therefore, this measurement suggests that the oxide layer thickness is at least $0.2 \mu \mathrm{m}$ on the surface of the struts in the as-prepared Co foam. The EDS measurement with a higher electron energy of $20 \mathrm{keV}$ gave $16 \pm$ 2 at. $\%$ for the oxygen concentration (see Table 2). The lower oxygen content was caused by the much larger penetration depth due to the higher electron energy, resulting in a higher contribution of the Co phase beneath the oxide layer. The penetration depth of electrons with an energy of $20 \mathrm{keV}$ in both $\mathrm{Co}_{3} \mathrm{O}_{4}$ and Co phases is about $1 \mu \mathrm{m}$. The oxide layer thickness in the as-prepared Co foam is calculated from these measurements as demonstrated in the discussion section. 
Table 2. The oxygen concentration measured using EDS at two different electron energies of 5 and $20 \mathrm{keV}$ for the as-prepared Co foam and the sample processed with 30 cycles of lithiation

\begin{tabular}{|c|c|c|c|c|}
\hline & \multicolumn{2}{|c|}{ As-received } & \multicolumn{2}{c|}{ After 30 cycles } \\
\hline Electron energy [keV] & 5 & 20 & 5 & 20 \\
\hline Oxygen concentration [at.\%] & $52 \pm 1$ & $16 \pm 2$ & $79 \pm 2$ & $26 \pm 3$ \\
\hline
\end{tabular}

After 30 cycles of lithiation/delithiation, no crystalline oxide phases were observed with XRD (see Figure 2). Despite the absence of a crystalline oxide phase, EDS detected a significant amount of oxygen as shown in Table 2. The oxygen concentrations measured with 5 and $20 \mathrm{keV}$ electron energies were $79 \pm 2$ at. $\%$ and $26 \pm 3$ at.\%, respectively. These values are much higher than the oxygen contents obtained for the as-prepared sample. Thus, it is concluded that lithiation resulted in amorphization of the crystalline oxide phases and an increase of the oxygen/cobalt ratio. In addition, the surface oxide layer was fragmented into scutes as shown in the SEM image in Figure 1d. The oxygen concentrations listed in Table 2 were determined in the interiors of these scutes (see circle A in Figure 1d as an example). For reference, Figure 1c shows the untreated surface of the asprepared Co foam with the same magnification, which did not reveal any fragmentation of the surface layer. In the lithiated material, there are channels between the scutes, which appear in a darker gray contrast in the SEM image in Figure 1d. Moreover, in some locations the scutes were peeled off from the surface (e.g., see location B in Figure 1d). In these parts, the oxygen content was much lower than in the interiors of the scutes. For instance, in the area indicated by circle B, the oxygen concentration was only about 9 at.\% as measured with the electron energy of $20 \mathrm{keV}$. The higher apparent oxygen concentration in the surface layer after 30 cycles of lithiation/delithiation can be explained by the Li content of the material. Li cannot be detected by EDS; therefore, if Li atoms remained in the surface layer in the Co foam after the last delithiation cycle, the actual oxygen concentration may be smaller than the measured value. Indeed, former studies have suggested that during lithiation, $\mathrm{Li}_{2} \mathrm{O}$ can form on the surface of Co foams. ${ }^{[12-16]}$ Therefore, the Li content was studied using ICP-MS and $0.29 \pm 0.03$ wt.\% was obtained for the 
entire material. Considering that the majority of the foam consists of $\mathrm{Co}$, the atomic fraction of $\mathrm{Li}$ was calculated as $\sim 2.4$ at.\%. Li was most likely concentrated in the surface layer of the struts; therefore, its atomic fraction should be very high in the outermost layer of the material. Indeed, XPS experiments revealed that the outermost surface layer contains $16 \pm 5$ at. $\% \mathrm{Li}$. The thickness of the surface layer studied by XPS was approximately $4 \mathrm{~nm}$. It is noted that XPS did not detect significant Co content in the outermost surface layer.

Due to the amorphous nature of the surface oxide layer, the density was unknown; therefore, calculation of the oxide layer thickness from a conventional EDS experiment was not feasible. Thus, an EDS scan on the ion-milled strut surface was performed in order to estimate the in-depth variation of the oxygen concentration. The schematic of the measuring configuration is shown in Figure 7a. The original strut surface and the ion-milled surface have an inclination angle of $6^{\circ}$. Therefore, the depth of the EDS spot from the original surface $(h)$ can be obtained as the product of the spot position $(s)$ and $\sin \left(6^{\circ}\right)$. Figure $7 \mathrm{~b}$ shows the measured oxygen concentration as a function of the depth from the strut surface $(h)$ in the lithiated foam. The oxygen concentration at $h=0 \mu \mathrm{m}$ is about 29 at. $\%$, which decreased to $\sim 3$ at. $\%$ for $h=0.37 \mu \mathrm{m}$. Further increases in $h$ did not yield any significant changes in the oxygen content; therefore, this depth value can be regarded as the thickness of the surface oxide layer in the lithiated material. The depth profile of oxygen concentration was also determined for the as-prepared sample (see Fig. 7b). The oxygen concentration decreased from about 16 at.\% to zero at $h=0.25 \pm 0.04 \mu \mathrm{m}$, suggesting that the thickness of the surface oxide layer almost did not change during lithiation. For further comparison, cross-sectional SEM and EDS mapping images of the as-prepared sample are also shown in Fig. 7c. The oxide layer thickness of the as-prepared sample observed on the SEM image in Fig. 7c is estimated as $\sim 290 \mathrm{~nm}$, which is in reasonable agreement with the $h$ value of $250 \mathrm{~nm}$ at the zero concentration of oxygen in the as-prepared sample (Fig. 7b). 
(a)

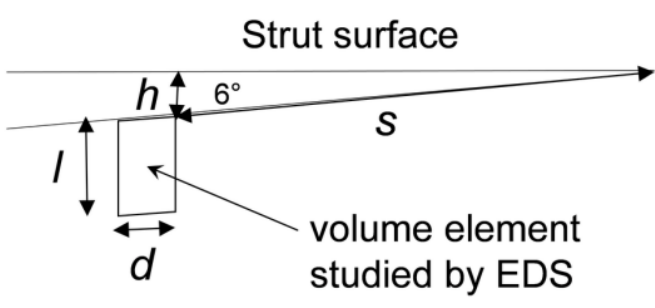

(b)

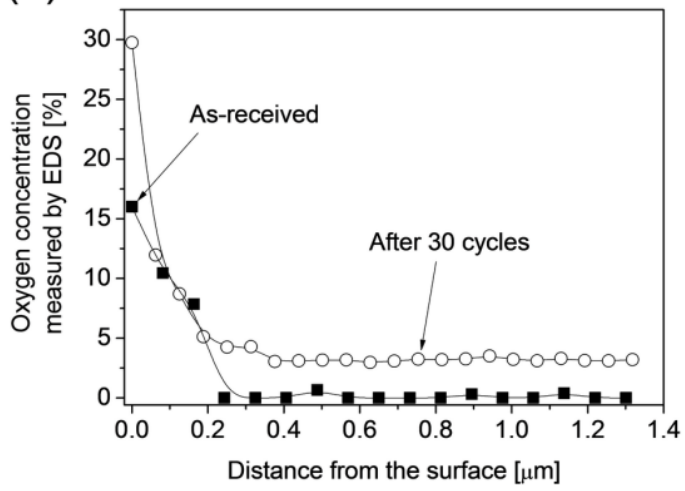

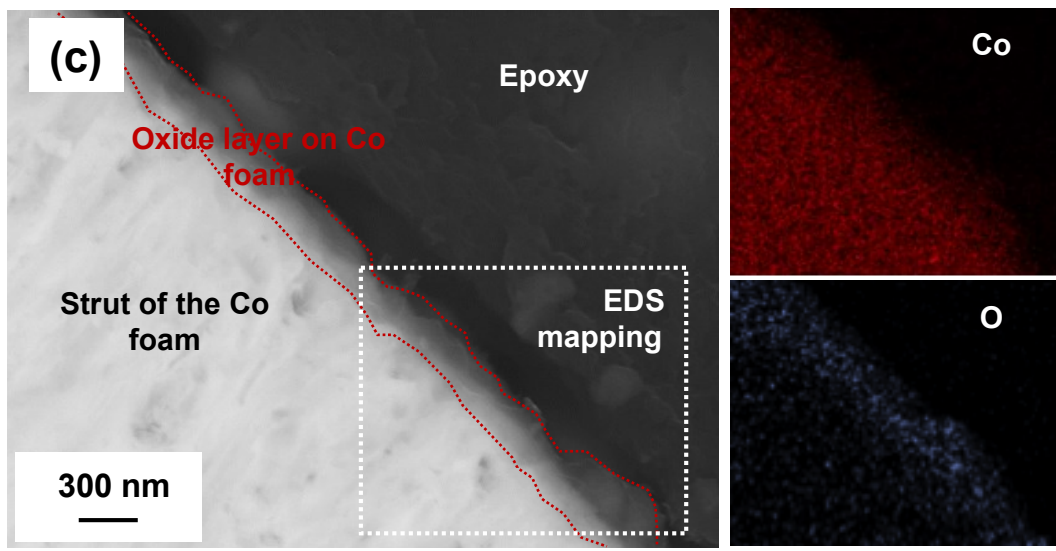

Figure 7. (a) The EDS measurement geometry for the determination of the in-depth spatial distribution of oxygen; (b) depth profile of oxygen concentration for the as-prepared sample and after 30 cycles of lithiation; (c) cross-sectional SEM and EDS mapping images of the as-prepared Co foam sample.

\section{Discussion}

From the oxygen concentration measured for the as-prepared material using EDS with $20 \mathrm{keV}$ electrons, the oxide layer thickness can be calculated as follows. It is assumed that the surface oxide layer comprises only $\mathrm{Co}_{3} \mathrm{O}_{4}$, with the thickness denoted by $x$ and a surface area equals to unity. The penetration depth of electrons is assumed to be larger than $x$ and denoted by $l$. Here, the value of $l$ depends on $x$. The ratio of the numbers of $\mathrm{O}$ and Co atoms (denoted by $N_{\mathrm{O}}$ and $N_{\mathrm{Co}}$, respectively) in the material penetrated by the electrons in the EDS experiments can be given as

$\frac{N_{O}}{N_{C o}}=\frac{4 n_{\mathrm{Co}_{3} \mathrm{O}_{4}}}{3 n_{\mathrm{Co}_{3} \mathrm{O}_{4}}+n_{\mathrm{Co}}}$ 
where $n_{\mathrm{Co}_{3} \mathrm{O}_{4}}$ is the number of $\mathrm{Co}_{3} \mathrm{O}_{4}$ groups in the $\mathrm{Co}_{3} \mathrm{O}_{4}$ layer with a unit area while $n_{C o}$ is the number of Co atoms in the Co strut beneath the oxide layer. The thickness of the latter material is $l$ $x$. The values of $n_{\mathrm{Co}_{3} \mathrm{O}_{4}}$ and $n_{\mathrm{Co}}$ can be expressed, respectively, as

$n_{\mathrm{Co}_{3} \mathrm{O}_{4}}=\frac{\rho_{\mathrm{Co}_{3} \mathrm{O}_{4}} \cdot x}{M_{\mathrm{Co}_{3} \mathrm{O}_{4}}}$

and

$n_{C o}=\frac{\rho_{C o} \cdot(l-x)}{M_{C o}}$

Here, $\rho_{\mathrm{Co}_{3} \mathrm{O}_{4}}\left(6.056 \mathrm{~g} \mathrm{~cm}^{-3}\right)$ and $\rho_{C o}\left(8.711 \mathrm{~g} \mathrm{~cm}^{-3}\right)$ are the densities while $M_{\mathrm{Co}_{3} \mathrm{O}_{4}}\left(241 \mathrm{~g} \mathrm{~mol}^{-1}\right)$ and $M_{C o}\left(59 \mathrm{~g} \mathrm{~mol}^{-1}\right)$ are the molar mass values of the $\mathrm{Co}_{3} \mathrm{O}_{4}$ and Co phases, respectively. Thus, the ratio of the numbers of $\mathrm{O}$ and $\mathrm{Co}$ atoms in the material studied by EDS can be expressed as

$\frac{N_{O}}{N_{C o}}=\frac{4 \frac{\rho_{\mathrm{Co}_{3} O_{4}}}{M_{C o_{3} O_{4}}} \cdot x}{3 \frac{\rho_{C O_{3} O_{4}}}{M_{C O_{3} O_{4}}} \cdot x+\frac{\rho_{C O}}{M_{C o}}(l-x)}$.

The thickness of the oxide layer $(x)$ can be calculated from Equation. (4) if the electron penetration depth $l$ is known; however, this value depends on the average density of the irradiated volume. A recently published work showed that the oxide layer thickness on the surface of asprepared Co struts is roughly $500 \mathrm{~nm} \cdot{ }^{[17]}$ As the penetration depth of electrons with the energy of 20 $\mathrm{keV}$ is ca. $1 \mu \mathrm{m}$ in both $\mathrm{Co}_{3} \mathrm{O}_{4}$ and Co phases, the average density of the material studied with EDS is approximated as the mean of the densities of the $\mathrm{Co}_{3} \mathrm{O}_{4}$ and $\mathrm{Co}$ phases $\left(7.4 \mathrm{~g} \mathrm{~cm}^{-3}\right)$. With this density value, the penetration depth is thus obtained as $\sim 1.3 \mu \mathrm{m}$ and the oxide layer thickness calculated from Equation. (4) is $0.32 \pm 0.05 \mu \mathrm{m}$ in the as-prepared Co foam. This value agrees within experimental error with the thickness determined from the EDS depth profile measurement (see Fig. 7b).

Figure 2 shows that lithiation of the Co foam resulted in the disappearance of the XRD peaks of the surface oxide layer. Similar phenomenon has already been observed for lithiated nanocrystalline $\mathrm{Co}_{3} \mathrm{O}_{4}$ film. ${ }^{[31]}$ From other experiments, it was suggested that during the first lithiation the $\mathrm{Co}_{3} \mathrm{O}_{4}$ phase transformed to $\mathrm{Co} / \mathrm{Li}_{2} \mathrm{O}$ composite where Co nanocrystals were embedded in the $\mathrm{Li}_{2} \mathrm{O}$ matrix. 
The subsequent delithiation resulted in the transformation of $\mathrm{Co}$ into $\mathrm{CoO}$ while $\mathrm{Li}_{2} \mathrm{O}$ also remained in the surface layer. During the first delithiation, $\mathrm{CoO}$ formed instead of $\mathrm{Co}_{3} \mathrm{O}_{4}$ in the $\mathrm{Li}_{2} \mathrm{O}$ matrix as the oxygen lattices in $\mathrm{Li}_{2} \mathrm{O}$ and $\mathrm{CoO}$ are nearly the same. These phase transformations during lithiation/delithiation of $\mathrm{Co}_{3} \mathrm{O}_{4}$ was also confirmed in other studies. ${ }^{[32-35]} \mathrm{Su}$ et al. showed that after delithiation very fine grained $\mathrm{CoO}$ while $\mathrm{Li}_{2} \mathrm{O}$ phases were formed with the grain size of $3-4 \mathrm{~nm} .^{[35]}$ If similar phase transformation occurred in the surface oxide layer of our Co foams during lithiation/delithiation, the grain size might be reduced to the nanometer level which might make the XRD peaks of the surface phases invisible in the diffractogram. For instance, if the grain size is only about $1 \mathrm{~nm}$, the XRD peak breadth increases to about $9^{\circ}$. Due to the high breadth and low intensity of XRD peaks, the surface phase seems to be amorphous. Thus, we can conclude that after 30 cycles of lithiation/delithiation the surface layer was apparently amorphous, although it might contain very small nanocrystals. It is worth to note that we studied a Co foam processed by freeze casting while the results of former works described above were obtained on $\mathrm{Co}_{3} \mathrm{O}_{4}$ films or particles. Therefore, in our case a full amorphization of the surface layer cannot be ruled out. XPS study reveals that there is no considerable cobalt in the outermost surface layer with the thickness of about $4 \mathrm{~nm}$, thus concluding that $\mathrm{Co} / \mathrm{Li}_{2} \mathrm{O}$ composite surely did not form in this layer. The high lithium and oxygen contents on the surface suggest the development of lithium oxide in the outermost layer during 30 cycles of lithiation/delithiation.

A previous study revealed that in $\mathrm{Co}_{3} \mathrm{O}_{4}$ nanoplates the phase transformation to $\mathrm{Co} / \mathrm{Li}_{2} \mathrm{O}$ composite during the first lithiation resulted in a volume expansion of the material with the value of $30-40 \% .{ }^{[32]}$ Subsequent delithiation yielded a decrease of this volume expansion although about one third of the first expansion remained irreversible. In our case, similar volume change must occur in the surface layer during lithiation/delithiation. However, the in-depth variation of the oxigen concentration after the last delithiation cycle was probably associated with a dependence of the volume change on the distance from the surface. Most probably, the uppermost surface layer suffered the highest volume expansion during lithiation. Due to the lower expansion of underlying 
layer, compressive stresses might develop in the uppermost layer which could be relaxed by plastic deformation. Then, subsequent delithiation yielded a shrinkage of the uppermost layer, resulting in cracking and fragmentation into scutes as shown in Figure 1d. It is noted that the deformation caused by the volume change was restricted within the surface layer and did not spread into the main Co phase of the struts as indicated by the unchanged XRD peak breadths (see Figure 6).

To the knowledge of the authors this is the first study in the literature which investigated the effect of lithiation on the microstructure of surface oxidized Co foam processed by freeze casting and revealed the gradient in the surface oxide layer after the last delithiation cycle (see Figure $7 b$ ).

The thickness of the highly oxidized surface layer after the $30^{\text {th }}$ delithiation cycle can be estimated from Figure $7 \mathrm{~b}(\sim 0.37 \mu \mathrm{m})$. It should be noted, however, that the $\mathrm{O}$ concentration at a depth $h$ characterizes a volume element with a diameter of ca. $d=0.3 \mu \mathrm{m}$ and a height of ca. $l=1.3 \mu \mathrm{m}$ due to the penetration of electrons into the material (see Figure 7a). Therefore, the actual local O concentrations differ from the data shown in Figure 7b, except at $h>0.37 \mu \mathrm{m}$, where there is no concentration gradient; however, for $h<0.37 \mu \mathrm{m}$, the actual local concentrations are higher than the measured values due to this effect. As also supported by the high Li content of the foam, the $\mathrm{O}$ concentration measured by EDS should be indeed higher than the actual values. Nevertheless, the EDS scan suggested that (i) the oxide layer thickness did not change considerably and (ii) a strong gradient in the oxygen/cobalt ratio developed in the uppermost surface layer during lithiation. This effect may be attributed to the formation of a Li-oxide solid-electrolyte interface layer during discharge, which yielded an increased $\mathrm{O} / \mathrm{Co}$ ratio.

\section{Conclusions}

A cobalt foam with a porosity of $77.4 \%$ containing an oxidized surface was processed by freeze casting. The changes in the microstructure and the phase composition during 30 cycles of lithiation/delithiation were investigated using XRD, SEM, EDS, XPS and ICP-MS. The following conclusions were drawn from the results: 
1. In the as-prepared foam, the main phase in the struts was hcp-Co, with a fraction of $84 \%$. In addition, fcc-Co, $\mathrm{Co}_{3} \mathrm{O}_{4}$ and $\mathrm{CoO}$ phases were also detected with fractions of 9,6 and 1\%, respectively. The grain size in the main phase was $0.38 \pm 0.04 \mu \mathrm{m}$. Considerable changes in the phase composition and the grain size in the strut interiors were not observed during 30 cycles of charging/discharging.

2. Significant microstrains with a $10^{-3}$ order of magnitude were observed in the main hcp-Co phase from analysis of the XRD line profiles. This lattice strain in the strut interiors did not change during the 30 cycles of lithiation. The grain size determined by EBSD agreed well with the diffraction domain size obtained from XRD line profile analysis, suggesting a lack of subgrain structure in the grains of the Co foam.

3. In the as-prepared $\mathrm{Co}$ foam, the surface oxide layer contained crystalline $\mathrm{Co}_{3} \mathrm{O}_{4}$ and $\mathrm{CoO}$ phases. The thickness of this layer was determined using EDS as $0.32 \pm 0.05 \mu \mathrm{m}$. After thirty cycles of charging/discharging the surface oxide layer appeared to be amorphous without a considerable change of its thickness. In addition, a very strong gradient in the $\mathrm{O} / \mathrm{Co}$ atomic ratio developed in the surface layer and a considerable Li concentration ( 2.4 at.\%) was measured in the Co foam. XPS revealed that in the outermost surface layer the Li content was as high as $\sim 16$ at.\% and a considerable amount of cobalt could not be detected. These observations can be explained by the formation of a surface Li-oxide layer. These changes on the surface appear to be accompanied by a fragmentation of the surface oxide layer into scutes with sizes of $0.3-0.5 \mu \mathrm{m}$. 


\section{References}

[1] L. Ji, Z. Lin, M. Alcoutlabi, X. Zhang, Energy Environ. Sci. 2011, 4, 2682.

[2] J. Jiang, Y. Li, J. Liu, X. Huang, C. Yuan, X.W. Lou, Adv. Mater., 2012, 24, 5166.

[3] K. Persson, V.A. Sethuraman, L.J. Hardwick, Y. Hinuma, Y.S. Meng, A. van der Ven, V.

Srinivasan, R. Kostecki, G. Ceder, J. Phys. Chem. Lett. 2010, 1, 1176.

[4] Y.G. Guo, J.S. Hu, L.J. Wan, Adv. Mater. 2008, 20, 4384.

[5] U. Kasavajjula, C. Wang, A.J. Appleby, J. Power Sources 2007, 163, 1003.

[6] C.-M. Park, J.-H. Kim, H. Kim, H.-J. Sohn, Chem. Soc. Rev. 2010, 39, 3115.

[7] M.N. Obrovac, V.L. Chevrier, Chem. Rev. 2014, 114, 11444.

[8] M. Rosa Palacin, Chem. Soc. Rev. 2009, 38, 2565.

[9] N. Nitta, F. Wu, J. T. Lee, G. Yushin, Mater. Today 2015, 18, 252.

[10] B. Li, P. Gu, G. Zhang, Y. Lu, K. Huang, H. Xue, H. Pang, Small 2018, 14, 1702184.

[11] M. Zheng, H. Tang, L. Li, Q. Hu, L. Zhang, H. Xue, H. Pang, Adv. Sci. 2018, 5, 1700592.

[12] J.S. Do, C.H. Weng, J. Power Sources 2005, 146, 482.

[13] L. Zhang, P. Hu, X. Zhao, R. Tian, R. Zou, D. Xia, J. Mater. Chem. 2011, 21, 18279.

[14] N. Yan, L. Hu, Y. Li, H. Zhong, X. Hu, X. Kong, Q. Chen, J. Phys. Chem. C 2012, 116, 7227.

[15] Y. Fu, X. Li, X. Sun, X. Wang, D. Liu, D. He, J. Mater. Chem. 2012, 22, 17429.

[16] G. Huang, S. Xu, S. Lu, L. Li, H. Sun, ACS Appl. Mater. Interfaces 2014, 6, 7236.

[17] H. Park, H.-H. Cho, K. Kim, K. Hong, J.-H. Kim, H. Choe, D.C. Dunand, Acta Mater. 2018, $142,213$.

[18] X. Chen, B. Liu, C. Zhong, Z. Liu, J. Liu, L. Ma, Y. Deng, X. Han, T. Wu, W. Hu, J. Lu, Adv. Energy Mater. 2017, 7, 1700779.

[19] J.H. Um, H. Park, Y.-H. Cho, M. Glazer, D.C. Dunand, H. Choe, Y.-E. Sung, RSC Adv. 2014, 4,58059 . 
[20] J.H. Um, M. Choi, H. Park, Y.-H. Cho, D.C. Dunand, H. Choe, Y.-E. Sung, Sci. Rep. 2016, 6, 18626.

[21] H. Park, J.-H. Um, M. Choi, Y.-E. Sung, H. Choe, Appl. Surf. Sci. 2017, 399, 132.

[22] W.-M Zhang, X.-L. Wu, J.-S. Hu, Y.-G. Guo, L.-J. Wan, Adv. Funct. Mater. 2008, 18, 3941.

[23] S.-M. Paek, E. Yoo, I. Honma, Nano Lett. 2009, 9, 72.

[24] H. Park, H. Choi, K. Nam, S. Lee, J.H. Um, K. Kim, J.-H. Kim, W.-S. Yoon, H. Choe, J. Electron. Mater., 2017, 46, 3789.

[25] H. Park, S. Lee, M. Jo, S. Park, K. Kwon, M. K. Shobana, H. Choe, J. Kor. Ceram. Soc. 2017, 54, 438.

[26] K. Feng, H.W. Park, X. Wang, D.U. Lee, Z. Chen, Electrochim. Acta 2014, 139, 145.

[27] J. Gubicza, X-ray Line Profile Analysis in Materials Science, IGI-Global, Hershey, 2014.

[28] R. F. Reilman, A. Msezane, S. T. Manson, J. Electron Spectrosc. Relat. Phenom. 1976, 8, 389.

[29] S. Evans, R. G. Pritchard, J. M. Thomas, J. Electron Spectrosc. Relat. Phenom. 1978, 14, 341.

[30] M. Mohai, Surf. Interface Anal. 2004, 36, 828.

[31] Z-W. Fu, Y. Wang, Y. Zhang, Q-Z. Qin, Solid State Ionics 2004, 170, 105.

[32] M.N. Obrovac, R.A. Dunlap, R.J. Sanderson, J.R. Dahn, J. Electrochem. Soc. 2001, 148, A576.

[33] D. Larcher, G. Sudant, J.-B. Leriche, Y. Chabre, J.-M. Tarascon, J. Electrochem. Soc. 2002, 149, A234.

[34] G-L. Xu, J-T. Li, L. Huang, W. Lin, S-G. Sun, Nano Energy 2013, 2, 394.

[35] Q. Su, J. Zhang, Y. Wu, G. Du, Nano Energy 2014, 9, 264. 